\title{
General Practitioners' views on the provision of nicotine replacement therapy and bupropion Andy McEwen ${ }^{* 1}$, Robert West ${ }^{1}$ and Lesley Owen ${ }^{2}$
}

Address: ${ }^{1}$ St George's Hospital Medical School Cranmer Terrace, London SW17 oRE, UK and ${ }^{2}$ Health Development Agency, Trevelyan House 30 Great Peter Street, London SW1P 2HW, UK

E-mail: Andy McEwen* - amcewen@sghms.ac.uk; Robert West - r.west@sghms.ac.uk; Lesley Owen - lesley.owen@hda-online.org.uk *Corresponding author

\begin{abstract}
Background: Nicotine replacement therapies (NRT) and a new drug, bupropion, are licensed in several countries as aids to smoking cessation. General practitioners (GPs) play a crucial role in recommending or prescribing these medications. In the UK there has been discussion about whether the medications should be reimbursable by the National Health Service (NHS). This study assessed English GPs' attitudes towards reimbursement of NRT and bupropion.
\end{abstract}

Methods: Postal survey of a randomly selected national sample of GPs; 376 GPs completed the questionnaire after one reminder; effective response rate: $53 \%$. There was no difference between the responses of GPs who responded to the initial request and those who responded only after a reminder suggesting minimal bias due to non-response.

Results: Attitudes of GPs were remarkably divided on most issues relating to the medications. Forty-three percent thought that bupropion should not be on NHS prescription while $42 \%$ thought that it should be (15\% did not know); Fifty percent thought that NRT should not be on NHS prescription while $42 \%$ thought it should be ( $8 \%$ did not know). Requiring that smokers attend behavioural support programmes to be eligible to receive the medications on NHS prescription made no appreciable difference to the GPs' views. GPs were similarly divided on whether having the medications reimbursable would add unacceptably to their workload or offer a welcome opportunity to discuss smoking with their patients. A principal components analysis of responses to the individual questions on NRT and bupropion revealed that GPs' attitudes could be understood in terms of a single 'pro-con' dimension accounting for $53 \%$ of the total variance which made no distinction between the two medications.

Conclusions: GPs in England appear to be divided in their attitudes to medications to aid smoking cessation and appear not to discriminate in their views between different types of medication or different aspects of their use. This suggests that their attitudes are generated by quite fundamental values. Addressing these values may be important in encouraging GPs to adhere more closely to national and international guidelines. 


\section{Background}

The causal link between smoking and increased morbidity and mortality is firmly established; 3 million people globally are estimated to die each year as a result of smoking [1]; about half of these die in middle age or before [2]. Smokers are less fit than non-smokers, they suffer more from both minor and major illness, and they feel less healthy [3].

Nicotine replacement therapy (NRT) [4] and bupropion (Zyban) [5,6] are both effective aids to smoking cessation. In the UK, from April 2001, bupropion joined NRT as an approved medication for the treatment of nicotine dependence and both are now available on NHS prescription. Both medications are also available to smokers wanting to quit in the United States of America, Australia, New Zealand and France.

In the UK General Practitioners (GPs) have an important role in recommending or prescribing stop smoking medications. The English National Smoking Cessation Guidelines [7] recommended that GPs should recommend, provide accurate information on and prescribe NRT or bupropion. US guidelines and new European guidelines also place considerable emphasis on the use by GPs and other health professionals of NRT and bupropion [8].

General practice is a key area in which the battle to reduce smoking prevalence in the UK will be won or lost; $99 \%$ of the population are registered with a GP [9] and about $80 \%$ of people consult with their GP at least once a year [10], the figure being even higher for smokers [11]. The evidence indicates that brief firm advice to stop smoking given by a GP to all known smokers, whether or not they want to stop, can lead to an increase in longterm (at least 12 month) cessation rates of about $1-2 \%$ [12].

However, a survey conducted in 1993 found that only $29 \%$ of smokers who had seen their GP in the previous 12 months said they had been given advice on smoking [13]. Previous studies have also indicated that interventions that are known to be cost-effective as a means of promoting smoking cessation are not being routinely implemented [13-15]. Depending upon GPs' views, the provision of NRT and bupropion on NHS prescription may prompt smoking cessation interventions.

When this survey was conducted (March to June 2000) most forms of NRT were on the NHS prescription blacklist, thus for most people NRT had to be obtained overthe-counter or on a private prescription. Bupropion was still to be approved by the Medicines Control Agency and there was debate as to whether it should be available on the NHS or whether patients should have to pay for it. This survey was conducted to assess GPs' attitudes towards NRT and bupropion being available on NHS prescription and whether such a prescription should only be issued if patients are willing to receive behavioural support or counselling. GPs were also asked how helpful NRT and bupropion being available on prescription would be in raising the topic of smoking cessation with patients, whether this would add unacceptably to their workload and if it was an appropriate use of NHS resources. Information on the gender, smoking status and age of all respondents was collected. GPs were also asked where their practice was situated, including a question about whether any of their patients lived in a 'Health Action Zone' (HAZ), and whether they worked alone or in a group practice. HAZs are areas of deprivation with identified local health needs whose health service providers receive additional funding from the Department of Health. About a quarter of the English population live in HAZs. The availability of funding to develop smoking cessation services in HAZs occurred in 1999, a year prior to other health authorities.

\section{Sample and methods}

This was a postal survey of a random sample of GPs in England and Wales conducted between March and June 2000. A National Department of Health GP database was used to generate the sample. This database is updated every three months. Random numbers were used to generate 1003 names and addresses from the total population. There were 726 usable names and addresses of individual GPs. Questionnaires were sent to this sample and 247 were completed and returned. In 17 further cases the questionnaire was returned uncompleted because the GP had moved away. A second mailing was sent to the non-responders four weeks later which yielded a further 128 responses and 8 uncompleted questionnaires returned because the GP had moved away. The 375 respondents represented an absolute response rate of $52 \%$ and the effective response rate based on those known to have actually received the questionnaire was $53 \%$.

Seventy-nine percent of respondents were male; the proportion found among GPs nationally is $68 \%$ [16]. The age distribution of respondents did not closely resemble the national distribution with an over-representation of GPs over 60 years of age [16]: (national figures are in brackets): $<30=1.9 \%(1.2 \%), 30-39=26 \%(33 \%), 40-49=$ $18 \%(36 \%), 50-59=19 \%(23 \%)$ and $>60=35 \%(6.2 \%)$. National statistics reveal that $30 \%$ of GPs in England and Wales work in single-handed practices and 70\% in practices with more than one GP [17], compared with $11 \%$ and $89 \%$ respectively with our respondents. A total of $32.5 \%$ of respondents in the sample reported that all or some of their practice patients lived in health action zones; $22 \%$ 
reported that their practices were in rural locations, $18 \%$ in inner city locations and $61 \%$ in "other urban" locations. Differences between the sample and the national demographics appear to have resulted from an interaction between the random number generation procedure and the structure of the NHS database used (involving a tendency which was not detected for older doctors to appear earlier in the database), and not bias in the types of GPs responding to the questionnaire. Deviations from the national demographics do not appear to have led to biases in key responses (see Results section).

A 16-item questionnaire was designed to identify: attitudes towards NRT and bupropion and demographic characteristics. The questionnaire was accompanied by a covering letter addressed to the doctor concerned and a FREEPOST envelope in which to return it.

\section{Results}

No significant differences were found between responses from the first and second wave of respondents suggest- ing that bias as a result of non-response was minimal [18].

Table 1 shows that opinion on whether bupropion should be reimbursed on NHS prescription was divided with $42 \%$ saying it should and $43 \%$ saying it should not. Opinion on the other questions was also divided although slightly more GPs thought having bupropion available on prescription would not add unacceptably to their workload than those that did.

The responses to the questions asked about the availability of NRT on NHS prescription closely resembled the responses to the questions relating to bupropion. Opinion was divided evenly although slightly more GPs thought having NRT available on prescription would not add unacceptably to their workload than those that did (Table 2).

Table I: Percentage of GPs responding to questions relating to the reimbursement of bupropion on NHS prescription

\begin{tabular}{|c|c|c|c|}
\hline & No & Don't know & Yes \\
\hline $\begin{array}{l}\text { I. Do you think that bupropion should be put on the prescription blacklist } \\
\text { once it has been approved by the MCA? }\end{array}$ & $42 \%(n=154)$ & $15 \%(n=56)$ & $43 \%(n=155)$ \\
\hline $\begin{array}{l}\text { 2. Do you think that bupropion should be available on NHS prescription to } \\
\text { smokers, but only if they are also willing to receive behavioural support or } \\
\text { counselling? }\end{array}$ & $48 \%(n=177)$ & $11 \%(n=41)$ & $41 \%(n=149)$ \\
\hline $\begin{array}{l}\text { 3. Do you think that having bupropion available on NHS prescription would } \\
\text { be useful in helping you to raise the topic of smoking with patients? }\end{array}$ & $45 \%(n=163)$ & $8 \%(n=30)$ & $47 \%(n=173)$ \\
\hline $\begin{array}{l}\text { 4. Do you think that having bupropion available on NHS prescription would } \\
\text { add unacceptably to your workload? }\end{array}$ & $50 \%(n=184)$ & $13 \%(n=49)$ & $36 \%(n=133)$ \\
\hline $\begin{array}{l}\text { 5. Do you think that having bupropion available on NHS prescription would } \\
\text { be an appropriate use of NHS resources }\end{array}$ & $42 \%(n=154)$ & $13 \%(n=47)$ & $46 \%(n=168)$ \\
\hline
\end{tabular}

Table 2: Percentage of GPs responding to questions relating to the provision of NRT on NHS prescription

\begin{tabular}{|c|c|c|c|}
\hline $\begin{array}{l}\text { 6. Do you think that NRT should be taken off } \\
\text { the prescription blacklist? }\end{array}$ & No $50 \%(n=183)$ & Don't know $8 \%(n=30)$ & Yes $42 \%(n=154)$ \\
\hline $\begin{array}{l}\text { 7. Do you think that NRT should be available on NHS prescription } \\
\text { to smokers, but only if they are also willing to receive behavioural }\end{array}$ & $51 \%(n=188)$ & $8 \%(n=30)$ & $40 \%(n=148)$ \\
\hline $\begin{array}{l}\text { 8. Do you think that having NRT available on NHS prescription } \\
\text { would be useful in helping you to raise the topic of smoking with } \\
\text { patients? }\end{array}$ & $47 \%(n=169)$ & $7 \%(n=26)$ & $46 \%(n=167)$ \\
\hline $\begin{array}{l}\text { 9. Do you think that having NRT available on NHS prescription } \\
\text { would add unacceptably to your workload? }\end{array}$ & $52 \%(n=187)$ & $12 \%(n=44)$ & $36 \%(n=130)$ \\
\hline $\begin{array}{l}\text { 10. Do you think that having NRT available on NHS prescription } \\
\text { would be an appropriate use of NHS resources? }\end{array}$ & $43 \%(n=156)$ & $9 \%(n=33)$ & $48 \%(n=172)$ \\
\hline
\end{tabular}


A principal components analysis of responses to the 10 items on NRT and bupropion indicated that the GPs' responses to all the questions reflected a single underlying attitudinal dimension. For this analysis the response 'No' was coded as 1, 'Don't know' as 2, and 'Yes' as 3. The analysis revealed that a single component accounted for $53 \%$ of total variance involving all the questions (a second component only accounted for $16 \%$ and a third for $11 \%$ ). The presence of a single coherent underlying scale was confirmed by a coefficient alpha, based on the 10 items (five each for NRT and bupropion), of 0.90. To examine specifically how far GPs' responses on NRT and bupropion were associated with each other, the five NRT ratings were totalled as were the five bupropion ratings and the two totals were correlated. The pearson correlation was $0.78(\mathrm{p}<001)$ indicating a very close association between attitudes to the two types of product.

Nearly a third $(32 \%, \mathrm{n}=117)$ of respondents in the sample reported that all or some of their practice patients lived in health action zones (HAZs). Those GPs working within HAZs $(33 \%, \mathbf{n}=37)$ were less likely than those GPs not in HAZ's $(46 \%, \mathrm{n}=116)$ to state that they thought that bupropion should be put on the prescription blacklist (chi-square $=7.402, \mathrm{p}<03$ ); although they were more likely to respond with a "don't know" (21\% against $13 \%$ respectively). Similarly GPs in HAZs (14\%, n = 16) were more likely to give a "don't know" response than GPs not in HAZs (6\%, $n=14$; Chi-Squared = 7.282, $\mathrm{p}<03$ ) to the question as to whether they thought NRT should be taken off the prescription blacklist. HAZ GPs $(13 \%, \mathbf{n}=15)$ were also more likely to say that they "don't know" whether NRT available on NHS prescription would help raise the topic of smoking with patients than non-HAZ GPs ( $5 \%, \mathrm{n}=11$; Chi-Squared $=8.731$, $\mathrm{p}, . \mathrm{O} 2)$. HAZ GPs $(36 \%, n=40)$ were less likely to think that bupropion should not be available on NHS prescription, but only if patients are willing to receive behavioural support or counselling, than GPs not working within HAZs ( $53 \%, \mathrm{n}=134$; Chi-Squared 9.786, $\mathrm{p}<008$ ). A parallel result was reported in relation to NRT with $57 \%$ (n $=142$ ) of GPs outside HAZ's reporting that NRT should not be available on prescription, even if conditional upon patients' willingness to receive support or counselling, compared with $39 \%(n=45)$ of HAZ GP's (Chi-Squared $=15.217, \mathrm{p}<01)$.

More respondents were male $(79 \%, \mathrm{n}=293)$ than the proportion found among GPs nationally (68\%) [9]. However, except that more male GPs $(51 \%, n=146)$ thought bupropion should only be available on prescription if accompanied by behavioural support or counselling than female GPs $(36 \%, n=29 ; p<01)$, there were no associations between gender and attitudes towards bupropion and NRT. Although the age distribution of respondents did not closely resemble the national distribution, with an over-representation of GPs over 60 years of age, there was no evidence of associations between age and attitudes towards bupropion and NRT. An apparent under representation of single-handed GP practices in this survey did not reveal any bias as no significant difference between single-handed and group-practice GPs were found. There were also no evidence of associations between where practices were situated (rural, inner city or other urban locations) and attitudes towards the availability of NRT and bupropion on NHS prescription.

\section{Discussion}

GPs were clearly divided in their attitudes to medications to help people stop smoking. Moreover they appeared to make little distinction between types of medication and their attitudes reflect a single 'pro-con' dimension. Previous surveys have revealed that most English GPs have not accepted that NRT is worth the cost even though the evidence indicates that in fact it is more than 10 times more cost effective as a life-preserving intervention and the average for medicine generally [19-21]. Our results suggest that a similar view may prevail for bupropion but that both may reflect more general value judgements about stop smoking medications and their place in the GPs' armamentarium. Possible bases for this general value judgement are failure to accept that nicotine dependence is a genuine medical disorder, lack of sympathy for a condition that is seen as self-inflicted, low absolute efficacy rates for the medications or other factors. On the face of it, it may seem difficult to reconcile our finding with other research showing that in principle most GPs accept that they have a role to play in smoking cessation [19] and research is needed into this issue to determine how best to encourage GPs to follow what national guidelines indicate is best practice. If it turns out that GPs are basing prescribing decisions in this area to some degree on personal values regarding smokers rather than the specific costs and benefits to health of the medications, this is clearly a matter for concern and attention would need to be directed at how to address this.

Those GPs within HAZ's appeared to hold a more positive, or more accurately a less negative, attitude towards NRT and bupropion. This may be as a result of the likelihood of there being a larger proportion of smokers amongst their patient population than in other health authorities. Alternatively it may be that Stop Smoking Services being established with HAZs at the time had, by raising awareness of smoking cessation and by the provision of services, produced a positive change in the attitudes of GPs.

Several factors may limit the generalisability of the findings. First the response rate was only just over 50 per 
cent and it may be that respondents were more likely to have strong views on the subject either way than non-respondents. However, the absence of a difference in responses between those who responded initially and those who only responded after a reminder lends some confidence that those who responded did not differ substantially from those who did not [18]. We have previously found in surveys of smoking cessation attitudes of GPs with response rates of 70 per cent that there was no difference between respondents in each of three waves lending further support to the view that non-response bias is limited in this kind of research [19]. In addition, even if the precise figures are incorrect the general conclusions about opinion being highly divided and being based on a single attitude dimension would not be expected to change. Secondly, the sample that responded was not representative of the GP population in a number of respects. However, responses to key items did not differ as a function of those demographic factors so this is unlikely to have affected the results. Thirdly, one might expect that attitudes would change over time and one would also expect attitudes in different countries to differ. However, we believe that it is useful for countries at different stages in the development of smoking cessation policies to be aware of the likelihood of substantial divisions of opinion among GPs and that these may be based on more fundamental values than a specific scrutiny of the evidence on particular types of medication. Since the survey was conducted NRT and Zyban have both been approved for reimbursement under the NHS and it would be interesting to see whether attitudes have changed accordingly in a follow-up survey.

\section{Conclusions}

GPs in England appear to be divided in their attitudes to medications to aid smoking cessation and appear not to discriminate in their views between different types of medication or different aspects of their use. This suggests that their attitudes are generated by quite fundamental values. Addressing these values may be important in encouraging GPs to adhere more closely to national and international guidelines.

\section{Competing interests}

Robert West has received travel funding, and undertaken research and consultancy for manufacturers of nicotine replacement therapies and bupropion.

\section{References}

I. Peto R, Lopez A, Boreham J, et al: Mortality from smoking worldwide. Tobacco and Health. (Edited by Doll, R. \& Crofton, J.) British Medical Bulletin 1996, 52:12-21

2. Health Education Authority: Revised Mortality Estimates from Smoking. London, HEA, 1996

3. Wald N, Hackshaw A: Cigarette smoking: an epidemiological overview Tobacco and Health. (Edited by Doll, R. \& Crofton, J.) British Medical Bulletin 1996, 52:3-II
4. Silagy C, Mant D, Fowler G, et al: Nicotine replacement therapy for smoking cessation. Cochrane Database Systematic Review 1999, 2:CD000I 46

5. Hurt R, Sachs D, Glover E, et al: A comparison of sustained-release bupropion and placebo for smoking cessation. NEJM 1997, 337:

6. Jorenby D, Leischow S, Nides M, et al: A controlled trial of sustained-released bupropion, a nicotine patch, or both for smoking cessation. NEJM 1999, 340:

7. West R, McNeill A, Raw M: Smoking cessation guidelines for health professionals: an update. Thorax 2000, 55:987-999

8. Raw M: US guideline and the new WHO European guideline: WHO Evidence-based Recommendations on the Treatment of Tobacco Dependence. Copenhagen: World Health Organsation, 2001

9. Health Education Authority, Rudat K: Health and Lifestyles: Black and Minority Ethnic Groups in England. London, HEA, 1994

10. Fowler G: Smoking cessation: the role of general practitioners, nurses and pharmacists. The Tobacco Epidemic (Edited by Bollinger, C. \& Fagerstrom, K.) Basel, Karger, 1997|65-I77

II. Office of Population Censuses and Surveys: General Household Survey 1994. London, The Stationary Office, 1996

12. Silagy C, Ketteridge S: The effectiveness of physician advice to aid smoking cessation. The Cochrane Library Issue 2. Oxford: Update Software. Updated quarterly, 1997

13. Health Education Authority: Health in England. London, HEA, 1995

14. Boulton $M$, Williams $A$ : Health education in general practice consultations: doctors' advice on diet, smoking and alcohol Health Education Journal 1983, 42:57-63

15. Wilson A, McDonald $P$, Hayes L, Cooney J: Health promotion in the general practice consultation: a minute makes a difference. British Medical Journal, 1992, 304:227-230

16. Department of Health: General Medical Services Statistics for England and Wales. Leeds, Department of Health, 1996

17. Martin R, Lunec S, Rink E: UK postal survey of pharmacists working with general practices on prescribing issues: characteristics, roles and working arrangements. The International Journal of Pharmacy Practice, 1998, 6:133-139

18. Brenner $\mathrm{H}$ : Alternative approaches for estimating prevalence in epidemiological surveys with 2 waves of respondents. American Journal of Epidemiology, 1995, I 42: I 236-1245

19. McEwen A, West R: Smoking cessation activities by general practitioners and practice nurses. Tobacco Control, 200I, 10:2732

20. Tengs T, Adams M, Pliskin J, Safran D, Siegal J, Weinstein M, Graham J: Five hundred life saving interventions and their cost-effectiveness. Risk Analysis, 1995, I 5:369-390

21. Parrott S, Godfrey C, Raw M, West R, McNeill A: Guidance for commissioners on the cost effectiveness of smoking cessation interventions. Thorax 1998, 53, Suppl 5 Pt 2:SI-38
Publish with BioMed Central and every scientist can read your work free of charge

"BioMedcentral will be the most significant development for disseminating the results of biomedical research in our lifetime." Paul Nurse, Director-General, Imperial Cancer Research Fund

Publish with BMC and your research papers will be:

- available free of charge to the entire biomedical community

- peer reviewed and published immediately upon acceptance

- cited in PubMed and archived on PubMed Central

- yours - you keep the copyright 